\title{
Therapeutic suppression of translation initiation modulates chemosensitivity in a mouse lymphoma model
}

\author{
Marie-Eve Bordeleau, ${ }^{1}$ Francis Robert, ${ }^{1}$ Baudouin Gerard, ${ }^{2}$ Lisa Lindqvist, ${ }^{1}$ Samuel M.H. Chen, ${ }^{1}$ \\ Hans-Guido Wendel, ${ }^{3}$ Brigitte Brem, ${ }^{4}$ Harald Greger, ${ }^{4}$ Scott W. Lowe, ${ }^{5}$ \\ John A. Porco Jr., ${ }^{2}$ and Jerry Pelletier ${ }^{1,6}$
}

\begin{abstract}
'Department of Biochemistry, McGill University, Montreal, Quebec, Canada. ${ }^{2}$ Department of Chemistry, Center for Chemical Methodology and Library Development, Boston University, Boston, Massachusetts, USA. ${ }^{3}$ Cancer Biology and Genetics Program, Memorial Sloan-Kettering Cancer Center, New York, New York, USA. ${ }^{4}$ Comparative and Ecological Phytochemistry Section, Faculty Center of Botany, University of Vienna, Vienna, Austria. ${ }^{5}$ Howard Hughes Medical Institute, Cold Spring Harbor Laboratory, Cold Spring Harbor, New York, USA. ${ }^{6}$ McGill Cancer Center, McGill University, Montreal, Quebec, Canada.
\end{abstract}

\begin{abstract}
Disablement of cell death programs in cancer cells contributes to drug resistance and in some cases has been associated with altered translational control. As eukaryotic translation initiation factor 4E (eIF4E) cooperates with c-Myc during lymphomagenesis, induces drug resistance, and is a genetic modifier of the rapamycin response, we have investigated the effect of dysregulation of the ribosome recruitment phase of translation initiation on tumor progression and chemosensitivity. eIF4E is a subunit of eIF4F, a complex that stimulates ribosome recruitment during translation initiation by delivering the DEAD-box RNA helicase eIF4A to the 5 ' end of mRNAs. eIF4A is thought to prepare a ribosome landing pad on mRNA templates for incoming 40S ribosomes (and associated factors). Using small molecule screening, we found that cyclopenta[b]benzofuran flavaglines, a class of natural products, modulate eIF4A activity and inhibit translation initiation. One member of this class of compounds, silvestrol, was able to enhance chemosensitivity in a mouse lymphoma model in which carcinogenesis is driven by phosphatase and tensin homolog (PTEN) inactivation or elevated eIF4E levels. These results establish that targeting translation initiation can restore drug sensitivity in vivo and provide an approach to modulating chemosensitivity.
\end{abstract}

\section{Introduction}

Dysregulation of protein synthesis occurs in many cancer cells harboring lesions in the PI3K/Akt pathway (1). This signaling cascade regulates mammalian target of rapamycin (mTOR) activity, which in turn controls translation initiation - the rate-limiting step of general protein synthesis (1). mTOR achieves this by controlling assembly of eukaryotic translation initiation factor (eIF) 4F, a complex that stimulates ribosome recruitment to mRNA templates. eIF4F is composed of 3 subunits: eIF4E, which binds to the cap structure present at the $5^{\prime}$ end of mRNAs; eIF4A, a DEAD-box RNA helicase implicated in preparing a ribosome landing pad for $43 \mathrm{~S}$ preinitiation complexes ( $40 \mathrm{~S}$ ribosomal subunit and associated factors) by unwinding 5 ' $\mathrm{mRNA}$ structure; and eIF4G, a large scaffolding protein involved in recruiting the $43 \mathrm{~S}$ preinitiation complex via its interaction with 40S-associated eIF3 (2). Ancillary factors, such as eIF4B and eIF4H, facilitate ribosome recruitment by stimulating eIF4A helicase activity (1).

mTOR regulates the availability of eIF4E and eIF4A for incorporation into the eIF $4 \mathrm{~F}$ complex $(1,3)$. The association of eIF4E with either eIF $4 \mathrm{G}$ or with one of 3 negative regulatory proteins, known as the eIF4E-binding proteins (4E-BPs), is under mTOR control (1).

Nonstandard abbreviations used: CBF, cyclopenta[b]benzofuran flavagline; 4E-BP, eIF4E-binding protein; eIF4E, eukaryotic translation initiation factor 4E; FA, 1-O-formylaglafoline; FF, firefly luciferase; IRES, internal ribosome entry site; mTOR, mammalian target of rapamycin; mTORC2, rictor/mTOR protein complex; PTEN, phosphatase and tensin homolog; Ren, Renilla luciferase.

Conflict of interest: The authors have declared that no conflict of interest exists. Citation for this article: J. Clin. Invest. 118:2651-2660 (2008). doi:10.1172/JCI34753.
4E-BPs and eIF4G occupy mutually exclusive binding sites on the surface of eIF4E. In their hypophosphorylated form, the 4E-BPs bind to and sequester eIF4E, leading to suppression of translation initiation (1). mTOR-mediated phosphorylation of 4E-BPs liberates eIF4E from this inhibitory complex and allows it to enter the eIF4F complex (1). The activity of eIF4A is regulated by binding to a tumor suppressor gene product, $\mathrm{Pdcd} 4$, which inhibits its helicase activity and its interaction with the $\mathrm{C}$-terminal domain of eIF4G (4). In response to mitogens, Pdcd 4 is phosphorylated by S6K1, a downstream target of mTOR, and subsequently degraded, leading to the release of eIF4A and its assembly into eIF4F (3).

Many lines of evidence suggest a direct link between deregulation of the ribosome recruitment phase of translation initiation and transformation. Increased eIF4F activity (5) and ectopic expression of eIF4E, eIF4G, or some of the eIF3 subunits can transform cells in culture (6-8). Overexpression of eIF4E cooperates with c-Myc during lymphomagenesis (9-11) by antagonizing its proapoptotic activities $(9,12-14)$, induces drug resistance, and leads to rapamycin resistance in vivo $(9,10)$. Altering translation initiation rates by inhibition of mTOR activity or ectopic overexpression of eIF4E remolds the oncoproteome by influencing the expression of a subset of cellular mRNAs - several of which have been implicated in cellular transformation (15-17). Strategies aimed at lowering eIF4E (18-20) or eIF4A (21) levels in transformed cells reduce malignant progression. Herein, we report that cyclopenta[ $b]$ benzofuran flavaglines (CBFs), compounds isolated from species of the Aglaia genus of the Meliaceae plant family, are novel inhibitors of translation initiation that act as chemical inducers of dimerization (CIDs), 


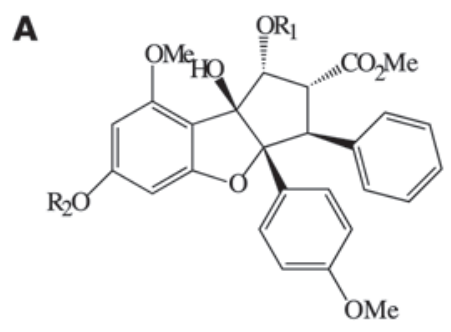
11-O-formylaglafoline (FA) : $\mathrm{R}_{1}=\mathrm{C}(\mathrm{O}) \mathrm{H}$ $\mathrm{R}_{2}=\mathrm{Me}$

2 Silvestrol: $\mathrm{R}_{1}=\mathrm{H}$

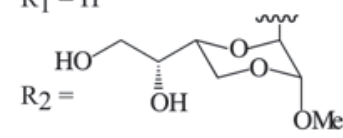

B

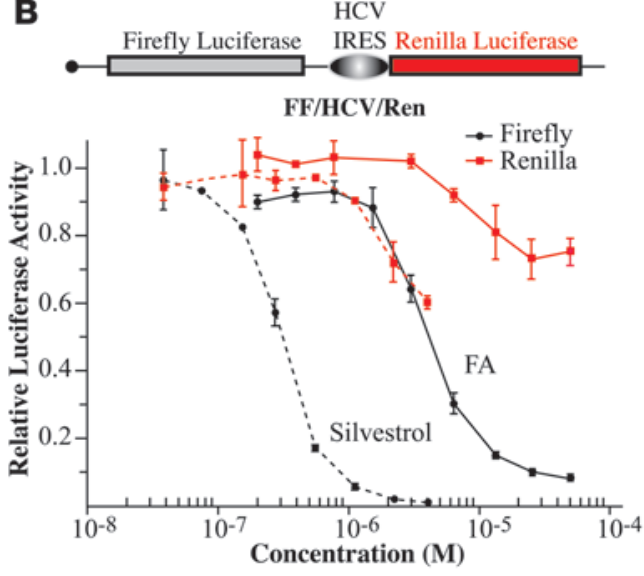

C

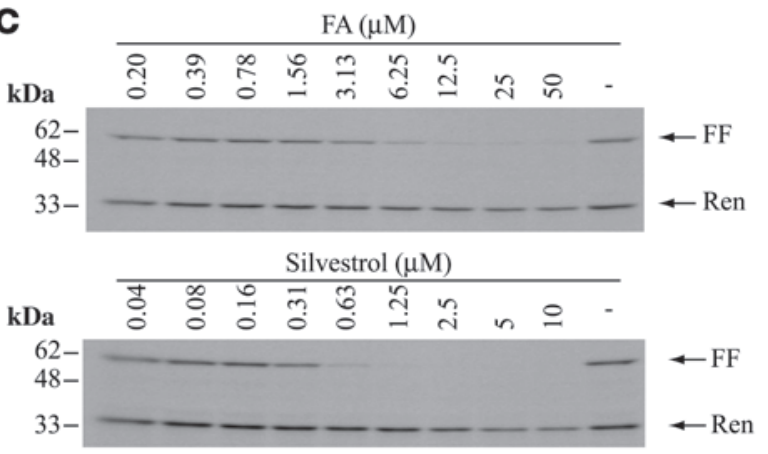

forcing an engagement between eIF4A and RNA. One member of this class of compounds, silvestrol (22), was able to alter chemosensitivity in E $\mu$-myc tumors harboring either a phosphatase and tensin homolog (PTEN) lesion or overexpressing eIF4E. These results suggest a strategy aimed at altering drug sensitivity in cancers by targeting translation initiation.

\section{Results}

CBFs are novel inhibitors of cap-dependent translation. During the course of a small molecule screening campaign designed to identify novel inhibitors of eukaryotic translation (23), a class of natural products, CBFs (also known as rocaglates), were found to exert potent inhibitory activity. Members of this family are known to be cytotoxic $(22,24-28)$ and inhibit protein synthesis $(25,29)$, but their molecular target(s) and mode of action are unknown. Two CBFs, 1-O-formylaglafoline (FA; also known as 1-O-formyl methyl rocaglate) and silvestrol (22) (Figure 1A), were identified and demonstrated a dose-dependent inhibition of cap-dependent firefly luciferase (FF) translation, but only a modest effect ( 2-fold decrease) on HCV internal ribosome entry site-mediated (HCV IRES-mediated) translation of Renilla luciferase (Ren) in an in vitro transla-

\section{Figure 1}

CBFs inhibit cap-dependent translation. (A) Chemical structure of FA and silvestrol. (B) FA and silvestrol inhibit cap-dependent translation. Top: Schematic representation of the FF/HCV/Ren mRNA. Bottom: Dose-dependent inhibition of cap-dependent protein synthesis by FA and silvestrol in Krebs-2 translation extracts programmed with $\mathrm{FF} / \mathrm{HCV} / \mathrm{Ren} \mathrm{mRNA}(10 \mu \mathrm{g} / \mathrm{ml})$. Luciferase activity (RLU) results are expressed relative to values obtained in the presence of vehicle $(\mathrm{MeOH})$ control. Results are expressed as mean \pm SEM of 2 experiments. (C) A representative autoradiograph from in vitro translations performed in Krebs-2 extracts with [ ${ }^{35}$ S]methionine and programmed with FF/HCV/Ren mRNA. The position of migration of FF and Ren proteins is indicated on the right.

tion assay (Figure 1, B and $\mathrm{C}$; $\mathrm{IC}_{50}$ for FF inhibition, $\sim 4 \mu \mathrm{M}$ and $0.3 \mu \mathrm{M}$ for FA and silvestrol, respectively) (see Discussion for an explanation of the HCV IRES-mediated translation effect). Rocaglates are active in several different eukaryotic cell-free translation systems (Figure 1 and Supplemental Figure 1; supplemental material available online with this article; doi:10.1172/JCI34753DS1), and silvestrol was approximately 10 -fold more potent than FA (Figure 1, B and C). These results suggest that CBFs preferentially target cap-dependent translation.

CBFs target IF4A and inhibit translation initiation. To identify the step of translation targeted by CBFs, we measured the effects of these compounds on the ribosome recruitment phase of translation initiation. In the presence of the elongation inhibitor cycloheximide, $80 \mathrm{~S}$ complexes were trapped at the AUG codon on radiolabeled mRNA templates and could be resolved by sedimentation velocity centrifugation (Figure 2A). FA inhibited 80S initiation complex formation and caused a concomitant increase in free mRNA, indicating an impairment of ribosome recruitment (Figure 2A).

Proper recruitment of the $43 \mathrm{~S}$ preinitiation complex to mRNA 5 ' ends is dependent on eIF4F, whose activity can be probed using a chemical cross-linking assay (30). Here, initiation factors (IFs) were cross-linked to the cap structure of radiolabeled mRNA and resolved by SDS-PAGE (Figure 2B). Cross-linking of eIF4E to the cap structure is ATP independent, whereas the cross-linking of eIF4A and eIF4B is ATP dependent (Figure 2B, compare lane 2 with lane 1), as previously reported (30). The binding of eIF4A, eIF4B, and eIF4E to mRNA is cap specific, since $\mathrm{m}^{7} \mathrm{GDP}$, but not GDP, causes a reduction in their cross-linking (Figure $2 \mathrm{~B}$, compare lanes 3 and 4 with lane 1). FA stimulated the cross-linking of eIF4A, but not of eIF4B and eIF4E, to mRNA (Figure 2B, compare lane 6 with lane 5). The increased cross-linking of eIF4A caused by silvestrol is cap specific and ATP dependent (data not shown).

eIF4A exists as a free form (eIF4A $A_{f}$ ) or as part of the eIF4F complex $\left(\mathrm{eIF}_{4} \mathrm{~A}_{c}\right)$ and is thought to recycle through eIF4F during translation initiation $(31,32)$. To assess the effects of CBFs on the RNAbinding activity of eIF $4 \mathrm{~A}_{\mathrm{f}}$ and $\mathrm{eIF} 4 \mathrm{~A}_{c}$, cross-linking experiments were performed using recombinant eIF4AI $\mathrm{I}_{\mathrm{f}}$ (Figure $2 \mathrm{C}$ ) or purified eIF4F (Figure 2D). FA and silvestrol stimulated the cross-linking of eIF4AI (Figure 2C, lanes 1-3) and eIF4A $_{c}$ (Figure 2D, compare lane 2 with lane 1) to mRNA. Consistent with the ability of CBFs to perturb eIF $4 \mathrm{~A}_{\mathrm{f}}$ activity, FA inhibited translation driven by the eIF4A-dependent encephalomyocarditis virus (EMCV) IRES (Supplemental Figure 2) (2). One possible mechanism by which CBFs might inhibit translation could be by inducing sequestration of eIF $4 A_{f}$ on RNA, such that less eIF4A is available for assembly into the eIF4F complex. 

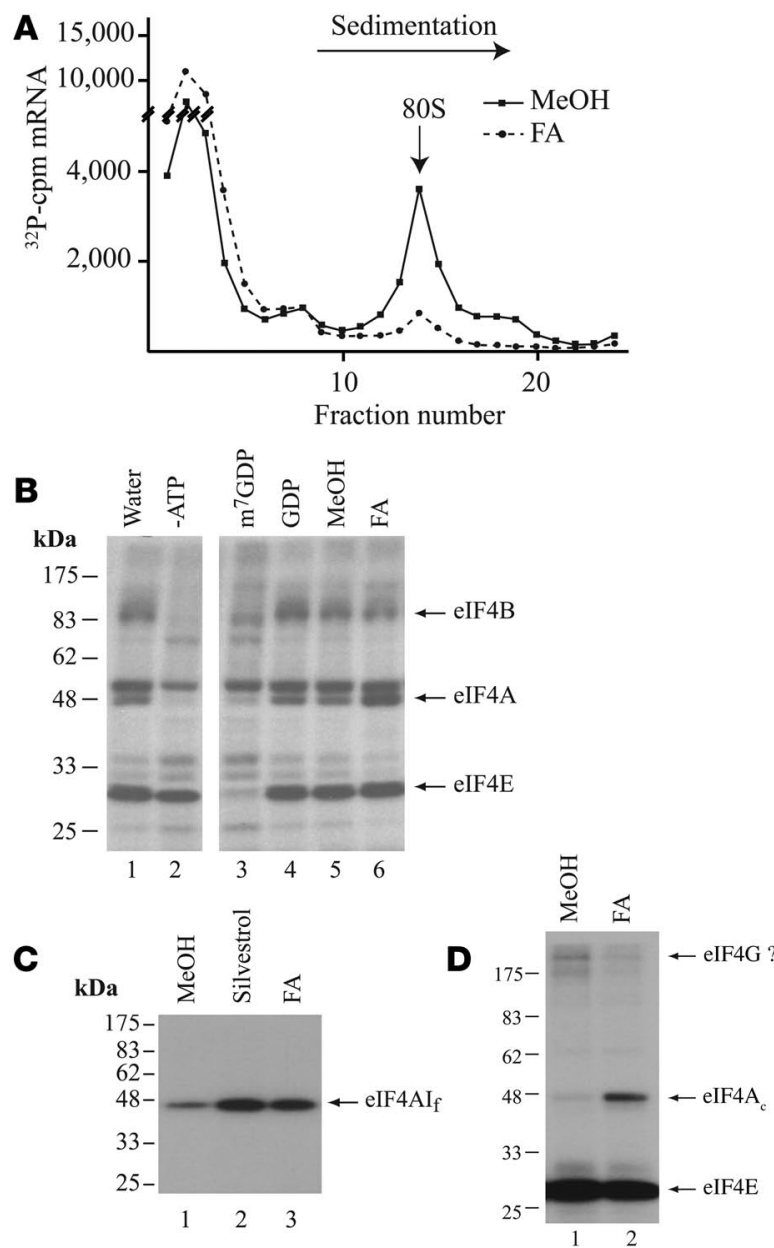

eIF4A is a member of the DEAD-box protein family comprising more than 35 members sharing 9 conserved amino acid motifs (33). We probed the selectivity of CBFs by testing the effects of FA on the activity of other DEAD-box proteins. FA did not stimulate cross-linking of Ded1 to mRNA (Supplemental Figure 3A, compare lane 4 with lane 3 ). We also tested the effect of FA on mRNA splicing, a process known to require the activity of more than 7 DEXD/H-box proteins (34) and found that in vitro splicing was not affected by FA (Supplemental Figure 3B, compare lane 4 with lane 3). These results, in addition to the findings that CBFs do not affect the RNA-binding activity of eIF4B and eIF4E (Figure 2B) or YB-1 (data not shown), indicate that these compounds show selectivity toward eIF4A.

CBFs inhibit translation in vivo and trigger apoptosis. To determine the potency of CBFs on protein synthesis in vivo, we performed metabolic labeling studies (Figure 3A). FA and silvestrol efficiently inhibited $\left[{ }^{35} \mathrm{~S}\right]$ methionine incorporation into proteins in a dosedependent manner, with silvestrol being more potent than FA in vivo (Figure $3 \mathrm{~A}, \mathrm{IC}_{50}$ for $\mathrm{FA}, \sim 0.1 \mu \mathrm{M}$; $\mathrm{IC}_{50}$ for silvestrol, $0.02 \mu \mathrm{M}$, for a 1-hour incubation). The potency of these compounds was much higher in vivo than in vitro (Figure 1A), and this may reflect differences in target accessibility; intracellular accumulation of the drug in vivo such that the concentration of drug in the media does not accurately reflect the concentration of drug inside the cell; or nonspecific sequestration of the drug in vitro by nontranslational

\section{Figure 2}

CBFs inhibit translation initiation and stimulate elF4A RNA-binding activity. (A) CBFs prevent $80 \mathrm{~S}$ complex formation. [32P]-labeled CAT mRNA $(200,000 \mathrm{cpm})$ was incubated with cycloheximide $(\mathrm{CHX})$ in the presence of $\mathrm{FA}$ or vehicle $(\mathrm{MeOH})$ in rabbit reticulocyte lysates. Reactions were resolved by centrifugation through glycerol gradients. Following centrifugation, fractions were collected and the amount of radioactivity determined by liquid scintillation counting. The total counts recovered from each gradient and the percentages of mRNA bound in $80 \mathrm{~S}$ complexes were: CAT mRNA/CHX + MeOH: $35,178 \mathrm{cpm}, 19 \%$ binding; and CAT mRNA/CHX + FA: $37,655 \mathrm{cpm}, 2 \%$ binding. (B) CBFs stimulate cross-linking of elF4A to mRNA. Initiation factor preparations were cross-linked to $\left.{ }^{32} \mathrm{P}\right]$-cap-labeled mRNA in the absence (lane 2) or presence of ATP (lanes 1 and 3-6), $0.6 \mathrm{mM} \mathrm{m}^{7} \mathrm{GDP}$ (lane 3), 0.6 mM GDP (lane 4), MeOH (lane 5), or $50 \mu \mathrm{M}$ FA (lane 6). Following nuclease digestion, samples were resolved by SDS-PAGE, and the gel was subjected to autoradiography. The position of migration of elF4E, elF4A, and elF4B is indicated and is based on their known behavior in this assay (30). (C) CBFs stimulate the RNA-binding activity of elF4Alf. $\left[{ }^{32} \mathrm{P}\right]$-cap-labeled $\mathrm{mRNA}$ was cross-linked to recombinant elF4Al $\mathrm{I}_{\mathrm{f}}$ in the presence of $\mathrm{MeOH}$ (lane 1), $50 \mu \mathrm{M} \mathrm{FA}$ (lane 3), or $50 \mu \mathrm{M}$ silvestrol (lane 2). Following nuclease digestion, samples were resolved by SDS-PAGE, and the gel was subjected to autoradiography. (D) CBFs stimulate the RNA-binding activity of elF4A $\mathrm{A}_{\mathrm{c}}$. [32P]-cap-labeled mRNA was cross-linked to elF4F in the presence of $\mathrm{MeOH}$ (lane 1) or $50 \mu \mathrm{M}$ FA (lane 2). Following nuclease digestion, samples were resolved by SDS-PAGE, and the gel was subjected to autoradiography. Crosslinking of a higher-molecular-mass species $(>175 \mathrm{kDa})$ is indicated by "elF4G ?" since it may reflect RNA-bound elF4G.

components of cell-free extracts. Nonetheless, these results indicate that CBFs are potent translation inhibitors in vivo. At FA and silvestrol concentrations that completely blocked protein synthesis, RNA $\left(\left[{ }^{3} \mathrm{H}\right]\right.$ uridine incorporation) and DNA $\left(\left[{ }^{3} \mathrm{H}\right]\right.$ thymidine incorporation) synthesis were not affected (Figure 3B), indicating that CBFs primarily target protein synthesis in vivo (25). To investigate whether the inhibition exerted by CBFs is reversible, the rate of $\left[{ }^{35} \mathrm{~S}\right]$ methionine incorporation was monitored in cells recovering from a translational block imposed by FA or silvestrol (Figure 3C). Translation rates were completely restored 8 hours following FA and silvestrol removal, although the rate of recovery from silvestrol inhibition was significantly slower (Figure 3C). These experiments do not address whether this is a consequence of differences in compound metabolism or binding affinity but do indicate that silvestrol is a more potent inhibitor of translation in vivo than FA.

The ability of CBFs to inhibit cap-dependent translation in vivo was assessed by monitoring luciferase production in cells transfected with the bicistronic reporter $\mathrm{pcDNA} / \mathrm{Ren} / \mathrm{HCV} / \mathrm{FF}$ in the presence of FA (Figure 3D). Cap-dependent translation was impaired by CBFs, whereas HCV IRES-mediated translation was slightly stimulated in vivo (Figure 3D). The effects of CBFs on translation in vivo were not due to mRNA degradation or activation of a cryptic promoter within the IRES, since mRNA integrity was not altered in cells following exposure to compound (Supple- 

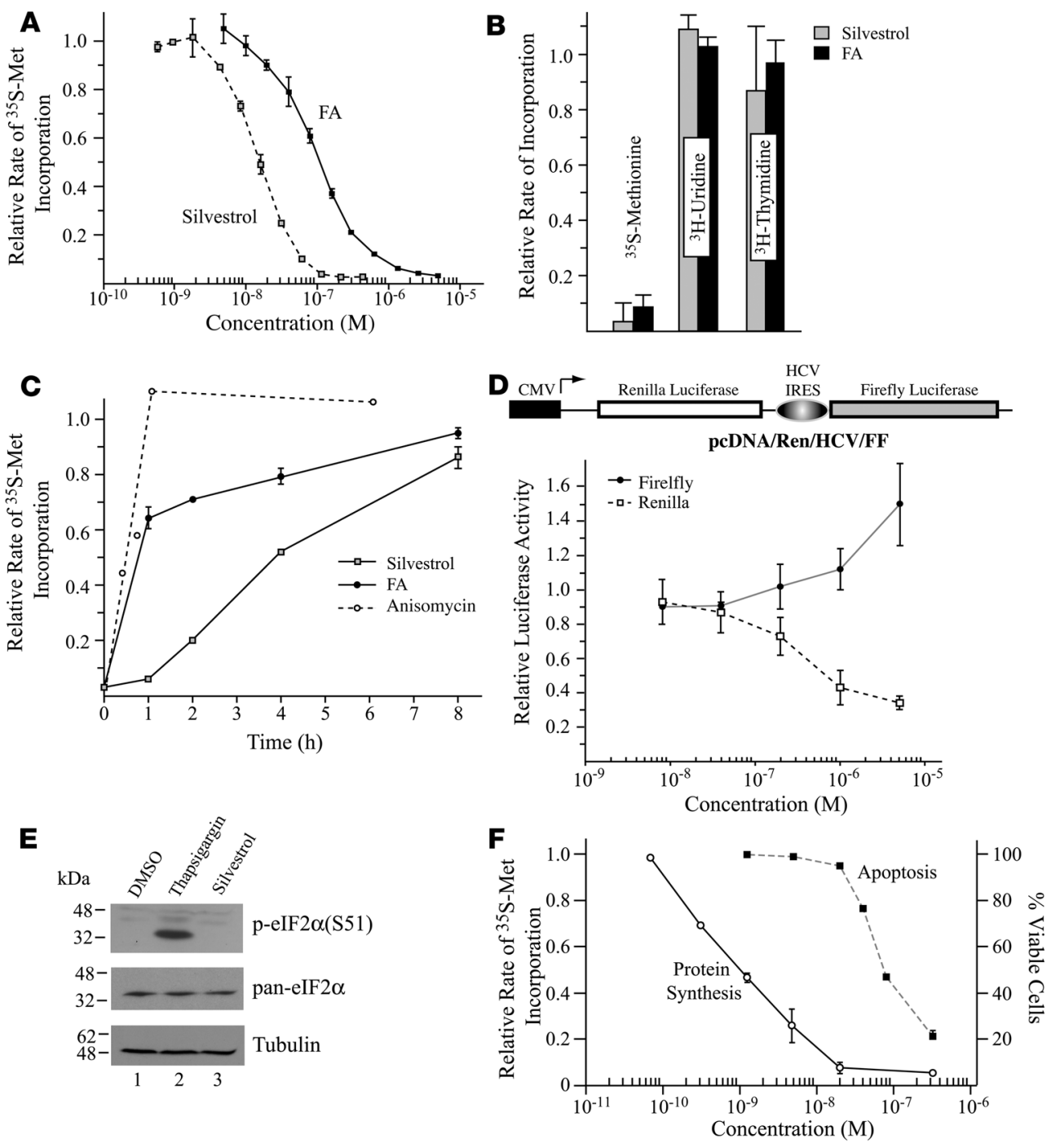

Figure 3

Effects of CBFs on protein, RNA, and DNA synthesis in vivo. (A) Dose-dependent inhibition of protein synthesis in vivo by CBFs. HeLa cells were incubated with the indicated concentrations of FA and silvestrol for 1 hour, with $\left.{ }^{35} \mathrm{~S}\right]$ methionine added 10 minutes before the end of the incubation. The rate of $\left[{ }^{35} \mathrm{~S}\right]$ methionine $\left.\left({ }^{35} \mathrm{~S}\right]-\mathrm{Met}\right)$ incorporation is expressed relative to that of cells treated with vehicle $(\mathrm{MeOH})$. Results are expressed as mean \pm SEM of 2 experiments. (B) CBFs primarily impact protein synthesis in vivo. HeLa cells were incubated with $5 \mu \mathrm{M}$ FA, $0.4 \mu \mathrm{M}$ silvestrol, or vehicle $(\mathrm{MeOH})$ for 1 hour. The rate of incorporation of each radioisotope tracer into TCA-insoluble material is expressed relative to that in $\mathrm{MeOH}$-treated cells. Results are expressed as mean \pm SEM of 2 experiments. (C) Inhibition of translation by CBFs is reversible. HeLa cells were incubated for 1 hour with $10 \mu \mathrm{M}$ anisomycin, $5 \mu \mathrm{M} \mathrm{FA}, 0.4 \mu \mathrm{M}$ silvestrol, or $\mathrm{MeOH}$. Cells were then washed with PBS and incubated with medium lacking compound for the indicated times. Ten minutes before harvesting, [ $\left.{ }^{35} \mathrm{~S}\right]$ methionine was added to the culture. The rate of $\left[{ }^{35}\right.$ S]methionine incorporation into TCA-insoluble material is expressed relative to that in $\mathrm{MeOH}$-treated cells. Results are expressed as mean \pm SEM of 3 experiments. Anisomycin acts a positive control, since recovery of protein synthesis from inhibition with this compound occurs within an hour of its removal from cells (65). (D) CBFs inhibit cap-dependent translation in vivo. Top: Schematic representation of pcDNA/Ren/HCV/FF expression vector. Bottom: Effect of FA on cap-dependent and HCV IRES-mediated translation in 293 cells transfected with pcDNA/Ren/HCV/FF. Luciferase activity is expressed relative to that in $\mathrm{MeOH}$-treated cells and is the mean \pm SEM of 2 experiments. (E) Silvestrol does not induce elF2 $\alpha$ phosphorylation. HeLa cells were incubated for 2 hours in the presence of vehicle (DMSO), thapsigargin $(2 \mu \mathrm{g} / \mathrm{ml})$, or silvestrol $(400 \mathrm{nM})$, after which extracts were analyzed by Western blotting. (F) Silvestrol induces apoptosis at concentrations higher than those required to inhibit protein synthesis. Jurkat cells were incubated with the indicated silvestrol concentrations for 13 hours, after which the rate of [ ${ }^{35}$ S]methionine incorporation or the percentage of living cells was measured. Results are expressed as mean $\pm \mathrm{SEM}$ of 2 experiments. mental Figure 4). In addition, since compounds that induce or sustain eIF2 $\alpha$ phosphorylation strongly inhibit protein synthesis, we assessed the ability of silvestrol to induced this event in vivo. Treatment of HeLa cells with thapsigargin (an ER stress inducer) or silvestrol strongly suppressed protein synthesis (Supplemental Figure 5). Whereas thapsigargin induced eIF $2 \alpha$ phosphorylation (Figure $3 \mathrm{E}$, compare lane 2 with lane 1 ), silvestrol did not (compare lane 3 with lane 2) at concentrations sufficient to inhibit protein synthesis. These results indicate that the inhibition of protein synthesis associated with silvestrol in vivo is not a consequence of eIF $2 \alpha$ phosphorylation.

CBFs have been previously shown to be capable of inducing apoptosis (24). To assess the dose required for this event versus that required for translation inhibition, Jurkat cells were exposed to various concentrations of silvestrol, and translation and cell death were monitored. At $80 \mathrm{nM}$, silvestrol induced apoptosis in approximately $50 \%$ of Jurkat cells following a 13-hour exposure (Figure $3 \mathrm{~F}$ ). However, a much lower concentration of silvestrol was sufficient to inhibit protein synthesis over this extended time period ( $\mathrm{IC}_{50}, 1 \mathrm{nM}$ ) (Figure $3 \mathrm{~F}$ ). These results indicate that the effects of CBFs on translation in vivo are not an indirect consequence of triggering apoptosis.

CBFs cause RNA-dependent sequestration of eIF4A in vivo. Given the ability of silvestrol to stimulate the RNA-binding activity of eIF4A in vitro, we wished to determine whether a similar mechanism was at work in vivo. Consequently, the position of migration of eIF4A was monitored in polysome profiles generated from Jurkat cells treated with silvestrol or vehicle (Figure 4). The profiles obtained in the presence of silvestrol were consistent with this compound inhibiting translation initiation 
A

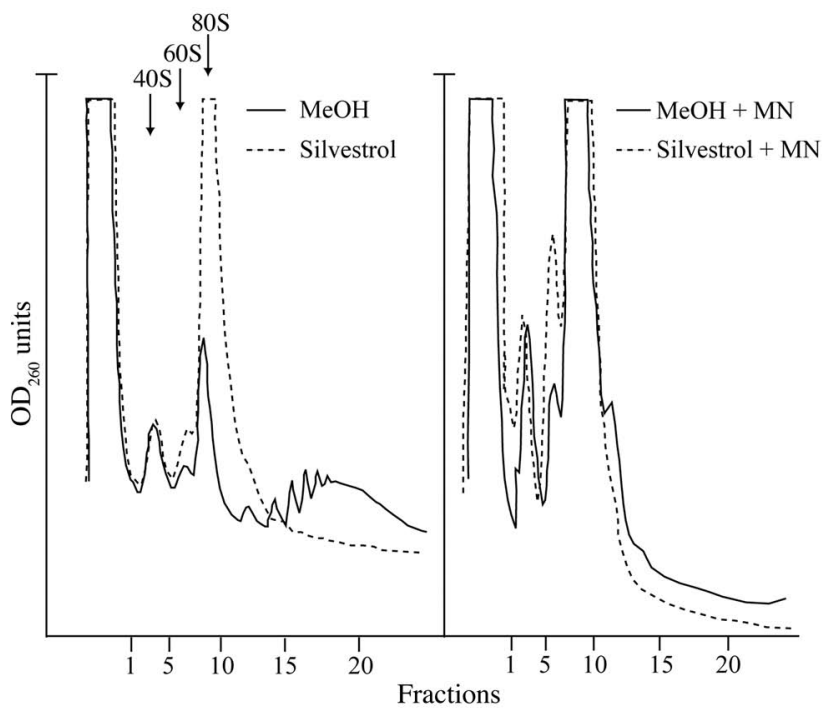

B

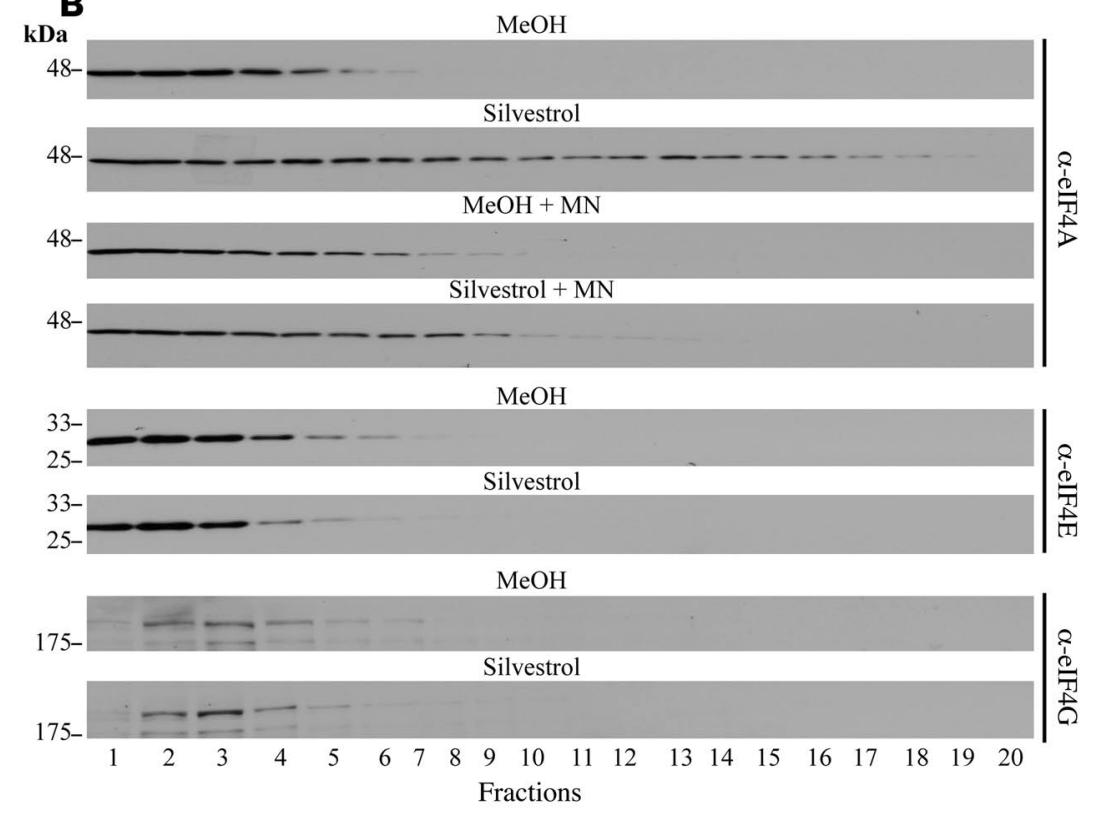

Figure 4

Silvestrol induces elF4A association into RNAsesensitive heavy sedimenting complexes in vivo. (A) Effect of silvestrol on Jurkat cell polyribosomes. Jurkat cells were exposed to vehicle $(\mathrm{MeOH})$ or $0.2 \mu \mathrm{M}$ silvestrol for 60 minutes. Cell extracts were prepared and treated with micrococcal nuclease (MN) where indicated. Reactions were resolved on $10 \%-50 \%$ sucrose gradients by centrifugation in an SW40 rotor at $150,000 \mathrm{~g}$ for 2 hours. Fractions were collected from the gradients and monitored with an ISCO UA-6 UV detector. (B) Western blots demonstrating the position of migration of elF4A, elF4E, and elF4G1 in sucrose fractions collected from untreated or $\mathrm{MN}$-treated lysates prepared from cells exposed to $\mathrm{MeOH}$ or $0.2 \mu \mathrm{M}$ silvestrol.

the consequences of inhibiting ribosome recruitment on chemosensitivity, silvestrol was tested in mice bearing lymphomas of different genotypes. We found that daily injections of silvestrol over a course of 8 days was well tolerated by mice and did not cause immunosuppression, weight loss, or impaired liver function (R. Cencic and J. Pelletier, unpublished observations). Doxorubicin and rapamycin synergized in mice bearing $\mathrm{Pten}^{+/-} \mathrm{E} \mu$ $M y c$ tumors and extended tumor-free survival to 12-16 days (Figure 5A; $P<0.0001$ for rapamycin plus doxorubicin versus rapamycin or doxorubicin alone). As a single agent, silvestrol showed no activity against $P$ ten ${ }^{+/} E \boldsymbol{\mu}-M y c$ lymphomas but did synergize with doxorubicin, with all animals achieving remissions that lasted up to 16 days (Figure 5A; $P<0.001$ for silvestrol plus doxorubicin versus silvestrol or doxorubicin alone). No synergy between silvestrol and doxorubicin was observed in $\mathrm{E} \mu-\mathrm{Myc} / \mathrm{Bcl}-2$ lymphomas, implying that the observed effect may be specific to tumors in which translation is deregulated (Figure 5B). Since $E \mu-M y c / e I F 4 E$ lymphomas are refractory to the combination of rapamycin and doxorubicin treatment (9) (Figure 5C), we tested the ability of

and allowing ribosome run-off (Figure 4A). Immunoblotting for eIF4A in fractions from these gradients revealed that silvestrol caused eIF4A to shift into heavier sedimenting fractions (Figure 4B). This shift was not observed with the eIF4E or eIF4G1 subunits of eIF4F (Figure 4B). Treatment of cell extracts with micrococcal nuclease prior to centrifugation prevented the shift of eIF4A toward heavier fractions (Figure 4B). These results suggest that silvestrol stimulates the RNA-binding activity of eIF4A in vivo.

Silvestrol reverses chemoresistance mediated by PTEN inactivation or eIF4E overexpression in E $\mathrm{\mu}-\mathrm{Myc}$ lymphomas. The E $\mu$-Myc murine lymphoma model is a powerful, genetically defined system for studying drug action in vivo. Activation of Akt signaling in this preclinical model accelerates tumorigenesis and promotes chemoresistance (9). The mTOR inhibitor rapamycin is capable of modulating sensitivity to doxorubicin and cyclophosphamide in Eu-Myc/myr-Akt and Pten ${ }^{+/-E \mu-M y c, ~ b u t ~ n o t ~ i n ~ E \mu-M y c / e I F 4 E, ~ l y m-~}$ phomas, suggesting that a significant proportion of Akt survival signaling is mediated by mTOR and $\operatorname{eIF} 4 \mathrm{E}(9,10)$. To investigate silvestrol to sensitize tumors of this genotype to doxorubicin. The Eu-Myc/eIF4E lymphomas did not respond to silvestrol alone (Figure 5C). Doxorubicin or the combination of doxorubicin/rapamycin induced remissions in approximately $60 \%$ of the animals that lasted on average only approximately 4 days (Figure 5C). The combination of silvestrol and doxorubicin produced a longer tumor-free survival than either single agent, with all animals achieving remissions lasting up to 25 days (Figure 5C; $P<0.001$ for silvestrol plus doxorubicin versus silvestrol or doxorubicin alone). These results clearly indicate that silvestrol plus doxorubicin treatment is more effective than rapamycin plus doxorubicin in this tumor type.

As previously reported (10), Pten ${ }^{+/} E \mu-M y c$ tumors harbored elevated levels of phosphorylated Akt and S6 (Figure 5D, compare lane 2 with lane 1). Rapamycin treatment of $\mathrm{Pten}^{+/-} \mathrm{E} \mu-M y c$ tumors inhibited mTOR activity, as judged by a reduction in p-S6 levels (Figure 5D, compare lane 3 with lane 2). Exposure of $\mathrm{Pten}^{+/}$E $\mu-M y c$ lymphomas to doxorubicin or silvestrol had no detectable effect on p-S6 or p-Akt levels (Figure 5D, compare lanes 5 and 6 with lane 4). 

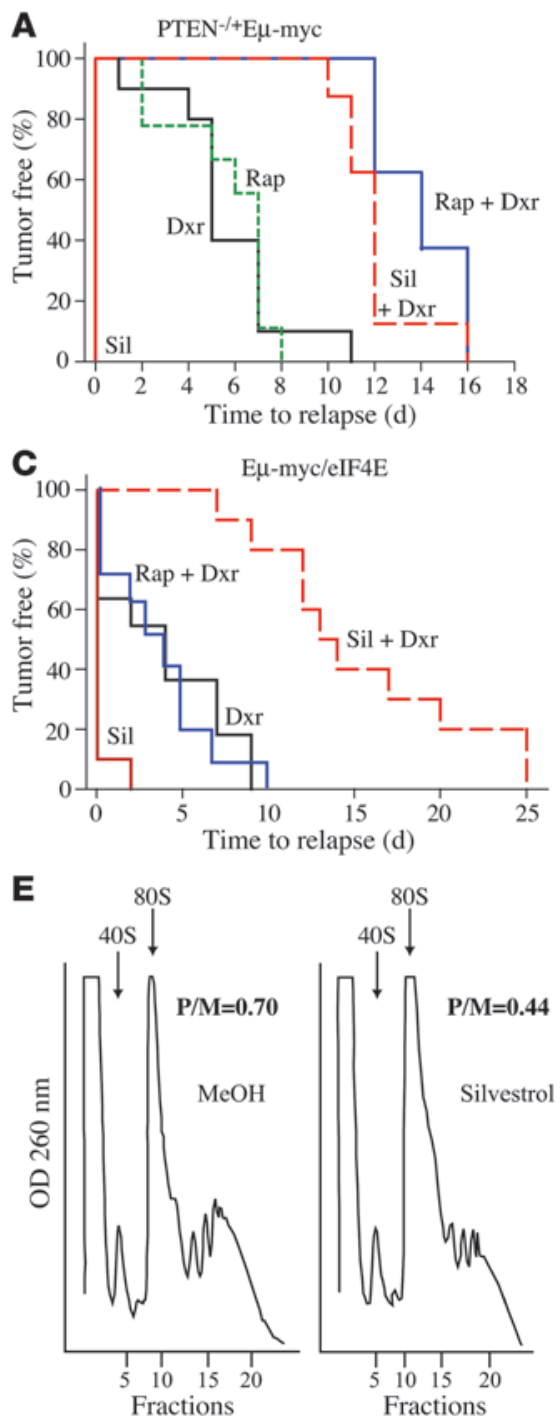

\section{Figure 5}

Silvestrol alters chemosensitivity in $\mathrm{Pten}^{+/-} E \mu-M y c$ and $E \mu-M y c / e l F 4 E$ tumors in vivo. (A) Silvestrol sensitizes Pten $^{+-} E \mu-M y c$ tumors to the effects of doxorubicin in vivo. Kaplan-Meier plot showing tumor-free survival of mice bearing Pten ${ }^{+-}$E $\mu-M y c$ tumors following treatment with doxorubicin (Dxr, solid black line; $n=10$ ), rapamycin (Rap, dashed green line; $n=9$ ), rapamycin and doxorubicin (Rap + Dxr; solid blue line; $n=8$ ), silvestrol (Sil, solid red line; $n=10$ ), or silvestrol and doxorubicin (Sil + Dxr, dashed red line; $n=8$ ). (B) Silvestrol does not alter drug response in $\mathrm{E} \mu-\mathrm{Myc} / \mathrm{Bcl}-2$ tumors in vivo. Kaplan-Meier plot showing tumor-free survival of mice bearing $E \mu$ $\mathrm{Myc} / \mathrm{Bcl}-2$ tumors following treatment with $\operatorname{Dxr}(n=9)$, Sil $(n=7)$, or Sil + Dxr $(n=8)$. (C) Silvestrol sensitizes E $\mu$ MycleIF4E tumors to the effects of Dxr in vivo. KaplanMeier plot showing tumor-free survival of mice bearing Eu-Myc/elF4E tumors following treatment with Rap + Dxr $(n=10)$, Dxr $(n=11)$, Sil $(n=10)$, or Sil + Dxr $(n=10)$. (D) Western blot analysis of Eu-myc/elF4E (lane 1) and Pten $^{+-}$E $\mu-M y c$ lymphomas (lanes 2-6). Lysates prepared from Eu-myc/elF4E or Pten ${ }^{+/} E \mu-M y c$ lymphomas from untreated (lanes 1, 2, and 4) and rapamycin- (lane 3), doxorubicin- (lane 5), and silvestrol-treated (lane 6) animals were subjected to immunoblotting for analysis of phosphorylated and total ribosomal S6 protein ( $p-S 6$ and S6) and Akt (p-Akt and Akt). (E) Silvestrol inhibits translation in Pten ${ }^{+-} E \mu-M y c$ tumors in vivo. Mice bearing $\mathrm{Pten}^{+/}$E $\mu-M y c$ tumors were injected with $\mathrm{MeOH}$ or silvestrol $(0.2 \mathrm{mg} / \mathrm{kg})$. Cytoplasmic extracts were prepared from tumors 4 hours later and resolved on $10 \%-50 \%$ sucrose gradients by centrifugation in an SW40 rotor at $150,000 \mathrm{~g}$ for 2 hours. Fractions were collected and monitored using an ISCO UA-6 UV detector. Plotted are results of 1 representative experiment of 3 that showed similar results. The positions in the gradients of $40 \mathrm{~S}$ and $80 \mathrm{~S}$ ribosomes are labeled, and the polysome/monosome (P/M) ratios are indicated.
To determine whether inhibition of translation was associated with this increased sensitivity to doxorubicin, we analyzed the polysome profile of tumors extracted from animals that had been treated with silvestrol (Figure 5E). As expected for an inhibitor of translation initiation, we found that the polysome to monosome ratio $(\mathrm{P} / \mathrm{M})$ in tumors treated with silvestrol decreased approximately $50 \%$ compared with that in nontreated tumors among 3 independent experiments (Figure 5E and data not shown). We blotted for eIF4E and eIF4A across the fractions from these polysomes to determine whether the reduction in $\mathrm{P} / \mathrm{M}$ ratio induced in vivo was also associated with a shift of eIF4A to heavier sedimenting RNA complexes (Supplemental Figure 6). As documented for silvestrol-treated cell lines (Figure 4B), eIF4A was also found in heavier sedimenting complexes in polysomes from $\mathrm{Pten}^{+/-} \mathrm{E} \boldsymbol{\mu}-\mathrm{Myc}$ tumors isolated from silvestrol-treated mice (Supplemental Figure 6). The lower amount of heavier sedimenting eIF4A-containing complexes observed for silvestrol-treated lymphomas compared with silvestrol-treated cells (Figure 4B) likely reflects the smaller effects of silvestrol on tumor polysomes (i.e., $50 \%$ reduction in polysomes in tumor samples compared with cell lines [compare Figure 5E with Figure 4A]).
We investigated the mechanism by which silvestrol was altering chemoresponsiveness of $\mathrm{Pten}^{+/}-E \mu-M y c$ tumors by analyzing a series of tumor samples 3 and 6 hours after treatment (Figure 6). TUNEL staining revealed an increase in apoptotic cells for the silvestrol/doxorubicin and rapamycin/doxorubicin combinations, compared with single-agent treatments with doxorubicin, silvestrol, or rapamycin (Figure 6, A and B). Inhibitors of apoptosis (IAPs) are known to block cell death and are regulated at the translational level, especially during stress (35). We did not detect changes in expression of XIAP, CIAP1, or CIAP2 in silvestrol-treated cells (data not shown) but did observe that treatments causing increased apoptosis also stimulated poly(ADP-ribose) polymerase (PARP) cleavage (Figure 6C, compare lanes 4 and 6 with lanes 1-3 and 5). These results demonstrate the effectiveness of targeting translation initiation to modulate chemoresponsiveness.

\section{Discussion}

Our results demonstrate that inhibiting translation initiation can modulate the response of transformed cells to chemotherapeutic insult. Inhibiting translation initiation induces apoptosis $(36,37)$, although the precise mechanism by which this event is triggered is 
A
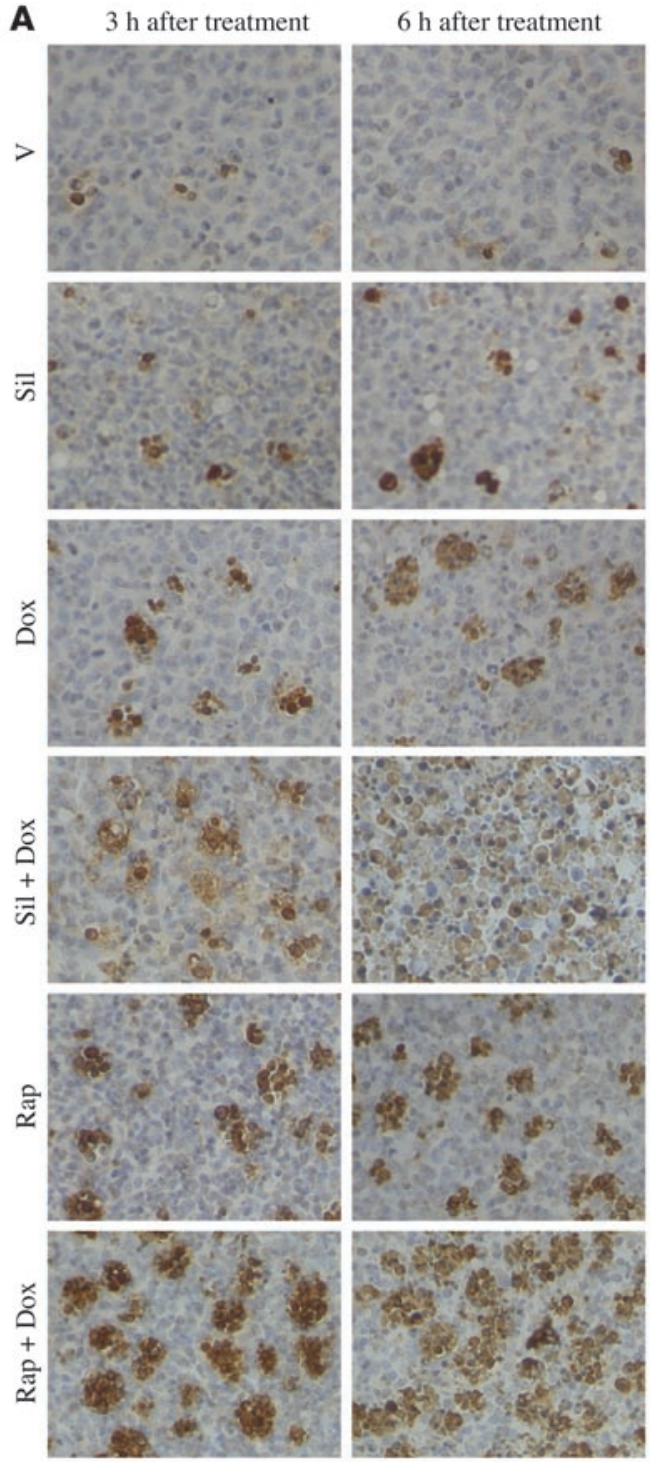

B
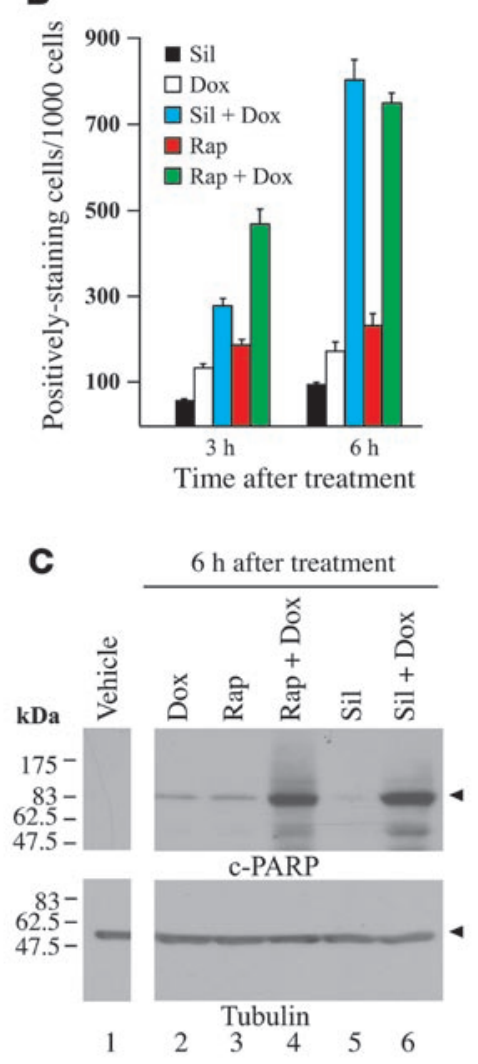

\section{Figure 6}

Silvestrol synergizes with doxorubicin to induce apoptosis in Pten ${ }^{+/-E} \mu-M y c$ lymphoma cells in vivo. (A) Representative micrographs (original magnification, $\times 200$ ) of $\mathrm{Pten}^{+-} \mathrm{E} \mu$ Myc lymphoma sections stained with $\mathrm{H} \& \mathrm{E}$ and TUNEL. C57BL/6 mice bearing well-palpable tumors were injected with vehicle, silvestrol, or rapamycin. Twenty-four hours later, the mice were injected again with silvestrol or rapamycin alone or in combination with doxorubicin. Three and 6 hours after treatment, tumors were extracted and stained. (B) Amount of tumor cells positive for TUNEL staining per 1,000 cells following the treatments described in $\mathbf{A}$. The cell count was obtained from 4 different fields taken from 2 different sections. Results are expressed as mean \pm SD. In vehicle-treated cells, there were $36 \pm 1$ TUNELpositive cells $/ 1,000$ cells. (C) Western blot analysis of $P t_{e n}+/-E \mu-M y c$ lymphomas treated as described in A. Tumor cells were extracted and lysed and the amount of cleaved poly(ADP-ribose) polymerase (c-PARP) and tubulin determined by Western blotting. not fully understood. One hypothesis is that changes in the levels or activity of eIF4F mediate the translational regulation of specific genes involved in survival and apoptosis (38). Gene-specific translational control is thought to be mediated by the amount of secondary structure within the $5^{\prime}$ untranslated region of mRNAs, which dictates the eIF $4 \mathrm{~A}_{c}$ requirement for ribosome recruitment (39). This is supported by the observation that altering eIF4F activity by ectopic overexpression of $\operatorname{IF} 4 \mathrm{E}(17,40)$ or rapamycin treatment (16) alters expression of a subset of mRNA transcripts involved in cell proliferation and apoptosis. Consistent with this hypothesis is the finding that a partial collapse of polysomes is observed in Pten $^{+/-E \mu-m y c ~ t u m o r s ~ e x p o s e d ~ t o ~ s i l v e s t r o l ~ i n ~ v i v o ~(F i g u r e ~ 5 D) . ~}$

The genotype-selective efficacy of silvestrol (in conjunction with doxorubicin) correlates with the expected occurrence of deregulated translation in these tumors. Since alteration of mTOR signaling in $\mathrm{Pten}^{+/}$Eu-myc lymphomas results in prosurvival signaling mediated by eIF4E (10), inhibition of translation initiation is expected to curtail this event and render tumors sensitive to DNA-damaging agents. The finding that silvestrol (in conjunction with doxorubi- cin) is effective against $\mathrm{Pten}^{+/-} \mathrm{E} \boldsymbol{\mu}-m y c$ and $E \mu-m y c / e I F 4 E$ tumors, but not against $E \mu-m y c / B c l 2$ lymphomas, is consistent with this hypothesis and suggests that the chemosensitizing effects of silvestrol are mediated by translation inhibition.

The effects of CBFs on translation reported herein are similar to those reported for pateamine, another small molecule inhibitor of translation initiation that also forces an engagement between eIF4A and RNA and prevents incorporation of eIF4 $\mathrm{A}_{\mathrm{f}}$ into the eIF4F complex $(41,42)$. Although both pateamine and CBFs stimulate eIF4A $\mathrm{A}_{\mathrm{f}} \mathrm{RNA}$-binding activity, only CBFs are capable of stimulating eIF4A $\mathrm{A}_{c}$ RNA-binding activity (Figure 2D) (41). In addition, pateamine is an extremely toxic compound, most likely due to the irreversible nature of its effects on translation (41), whereas the effects of CBFs on translation are reversible (Figure 3C). CBFs may thus act as chemical inducers of dimerization - forcing an interaction between eIF4A and RNA - suggesting that these compounds may impair the recycling of eIF4A $\mathrm{A}_{\mathrm{f}}$ into the eIF4F complex (32). CBFs have been reported to inhibit $\mathrm{mdm} 2$, nuclear factor of activated T cells (NF-AT), and NF-кB activity (43-45), and some 
of these other activities may be an indirect consequence of CBFs' effect on translation.

The mechanism of action of CBFs may explain the partial inhibition of HCV IRES-mediated translation (an eIF4A-independent process) observed at high CBF concentrations in vitro (Figure 1) (2), since CBF-mediated nonspecific binding of eIF $4 \mathrm{~A}_{\mathrm{f}}$ to the IRES could interfere with its function. In contrast, stimulation of $\mathrm{HCV}$ IRES-driven translation is observed in vivo in the presence of much lower concentrations of CBFs and may reflect the fact that 43S preinitiation complexes are limiting for HCV IRES-mediated translation and become available upon inhibition of cap-dependent translation (Figure 3D). This phenomenon has been previously reported for 2 other small molecule modulators of eIF4A activity $(42,46)$. Inhibition of translation initiation by RNA-mediated sequestration of $\mathrm{eIF} 4 \mathrm{~A}_{\mathrm{f}}$ is not unique to pateamine and CBFs, since this mechanism has been reported for BC1, a small, brainspecific noncoding RNA that represses translation at synaptodendritic microdomains $(47,48)$.

Deregulated expression of the eIF4F subunits has been implicated in the transformation process and drug resistance. The eIF4A subunit was shown to be overexpressed in human cancers, such as melanomas (49) and hepatocellular carcinomas (50). The availability of the eIF4 $\mathrm{A}_{\mathrm{f}}$ subunit for incorporation into the eIF4F complex is regulated by its association with the tumor suppressor gene product Pdcd4, a protein whose levels are reduced in human lung, renal, and glial tumors (51). Moreover, overexpression of Pdcd4 in the epidermis delays tumor onset and progression in a chemically induced murine skin tumor model (21). Ectopic overexpression of eIF4G and eIF4E is also oncogenic $(6,7)$, and the levels of the eIF4E subunit are elevated in many human cancers and have been proposed as an independent prognostic tumor marker for breast cancer $(52,53)$. Reciprocally, the levels of 4E-BP1, a negative regulator of eIF4E, inversely correlate with progression of colon cancers (54). eIF4E is also a genetic modifier of the rapamycin response in vivo (10). Rapamycin resistance is an emerging complex and important clinical problem (55) that is thought to result in part from weakening by rapamycin of a negative feedback loop from S6K to IRS-1, leading to activation of IGF-1 (and Akt) signaling. This would have the undesired consequence of reducing the antitumor effects of mTOR inhibitors (56). The prevalence of this mechanism in human cancers is not known. Long-term exposure to rapamycin also targets the rictor/mTOR protein complex (mTORC2) and leads to inhibition of Akt S473 in primary acute myeloid leukemias (57-59). Exposure of $\mathrm{Pten}^{+/}$Eu-myc lymphomas to rapamycin did not increase p-Akt levels, indicating that the S6K/IRS-1 loop is not operative in $\mathrm{Pten}^{+/-E \mu-m y c}$ lymphomas (Figure 5D and unpublished observations). Our experiments do not address the ability of CBFs to reverse general rapamycin resistance, but they do suggest that in situations where this is a consequence of elevated eIF4E expression, CBFs may be beneficial. Moreover, direct targeting of eIF4A by CBFs did not directly impact on the S6K/IRS-1 negative feedback loop or mTORC2directed Akt phosphorylation (Figure 5D), potentially conferring an advantage to CBFs over rapamycin in sensitizing cells to chemotherapy. CBFs prevented growth of human Jurkat (Figure 3F) and LNCaP cells in culture $(27,60)$ and have shown encouraging effects in xenograft tumor models (25), but their ability to synergize with other cytotoxic agents has not previously been tested. As a single agent, silvestrol, was ineffective against E $\mu$-myc lymphomas harboring PTEN lesions or overexpressing eIF4E (Figure 5,
A and C). This may be due to the fact that only partial inhibition of protein synthesis was observed upon silvestrol administration in vivo compared with in vitro experiments (Figure 5E). This level of inhibition may be sufficient to curtail prosurvival signaling, but below the threshold required to halt cellular proliferation. However, in combination with doxorubicin, silvestrol was effective against $\mathrm{Pten}^{+/-E \mu-m y c}$ and E $\mu-M y c / e I F 4 E$ tumors, the latter being refractory to rapamycin/doxorubicin treatment. We do not believe that an inherent feature of E $\mu$-myc lymphomas makes them particularly sensitive to the effects of silvestrol/doxorubicin combination, since $E \mu-m y c / B c l 2$ lymphomas were not sensitive to this drug combination (Figure 5B). Our results support the idea that curtailing translation initiation by modulating eIF4A activity is a promising approach to altering drug resistance associated with $\mathrm{PI} 3 \mathrm{~K} / \mathrm{mTOR}$ activation.

\section{Methods}

Compound isolation, synthesis, and storage. FA was isolated from the roots of Aglaia australiensis C. M. Pannell (HG 662) collected in Atherton Tablelands, Queensland, Australia. The methanolic extract was partitioned between water and chloroform, and the lipophilic fraction was separated by preparative medium pressure liquid chromatography and thin-layer chromatography as described previously (61). FA was also chemically synthesized using a previously described synthetic route (62). The synthetic derivative and natural product showed equivalent potency in translation inhibition assays. Silvestrol was a kind gift from Murray Tait (Cerylid Biosciences Ltd., Richmond, Victoria, Australia) (63). FA and silvestrol were resuspended in methanol and stored at $-70^{\circ} \mathrm{C}$. Doxorubicin (Sigma-Aldrich) was dissolved in water and stored at $4^{\circ} \mathrm{C}$. Rapamycin (LC Laboratories) was resuspended in $100 \%$ ethanol and stored at $-70^{\circ} \mathrm{C}$.

In vitro transcription and translation. For in vitro transcriptions, plasmids $\mathrm{pKS} / \mathrm{FF} / \mathrm{Ren}, \mathrm{pKS} / \mathrm{FF} / \mathrm{EMCV} / \mathrm{Ren}$, and $\mathrm{pKS} / \mathrm{FF} / \mathrm{HCV} /$ Ren were linearized with $\mathrm{BamHI}$ and transcribed with T3 RNA polymerase to generate mRNA. In vitro translations were performed using Krebs- 2 extracts at final mRNA and $\mathrm{K}^{+}$concentration of $5 \mu \mathrm{g} / \mathrm{ml}$ and $100 \mathrm{mM}$, respectively (23). FF and Ren activities (RLU) were measured on a Lumat LB 9507 luminometer (Berthold Technologies). Following in vitro translations in the presence of $\left[{ }^{35} \mathrm{~S}\right]$ methionine, protein products were separated on $10 \%$ polyacrylamide/ SDS gels that were treated with $\mathrm{EN}^{3} \mathrm{HANCE}$ (PerkinElmer), dried, and exposed to X-Omat (Kodak) film.

Cell culture, transfections, luciferase and apoptosis assays. For in vivo luciferase assays, 293 cells were maintained in DMEM medium supplemented with $10 \%$ FCS. The day before calcium phosphate transfection, cells were seeded at $3 \times 10^{6}$ cells $/ 10$-cm dish. Following transfection with $\mathrm{pcDNA} / \mathrm{Ren} / \mathrm{HCV} /$ FF, 293 cells were incubated for 10 hours with vehicle $(\mathrm{MeOH})$ or $\mathrm{CBF}$ before harvesting and were collected 48 hours after transfection. Luciferase assays were performed with the Dual-Luciferase assay kit according to the manufacturer's instructions (Promega). Probes for Northern blots were produced using the Rediprime kit (Amersham).

For annexin $\mathrm{V}$ binding assays, Jurkat cells were maintained in RPMI media supplemented with $10 \%$ FCS. Cells $\left(1 \times 10^{6}\right)$ were plated in 12 -well plates and incubated with vehicle $(\mathrm{MeOH})$ or silvestrol for 13 hours. Cells were harvested by centrifugation, washed with PBS, and resuspended in 500 $\mu \mathrm{l}$ annexin $\mathrm{V}$ binding buffer (10 mM HEPES, pH 7.4, $140 \mathrm{mM} \mathrm{NaCl}, 5 \mathrm{mM}$ $\mathrm{CaCl}_{2}$ ). Five microliters of annexin V-FITC (BD Biosciences - Pharmingen) was added, and the reactions were incubated for 5 minutes at room temperature in the dark. Propidium iodide (PI) was then added $(1 \mu \mathrm{g} / \mu \mathrm{l})$, and the reactions were incubated for another 5 minutes. The percentage of living cells (negative for annexin $\mathrm{V}$ and PI staining) was measured by flow cytometry and expressed relative to $\mathrm{MeOH}$-treated cells. 
In vivo metabolic labeling studies. Briefly, $6 \times 10^{4} \mathrm{HeLa}$ cells were seeded into 24-well plates 1 day prior to the experiment. Cells were incubated in the presence of compound or vehicle for the indicated periods of time. $\left[{ }^{35} \mathrm{~S}\right]$ methionine $(150-225 \mu \mathrm{Ci} / \mathrm{ml})$ and $\left[{ }^{3} \mathrm{H}\right]$ uridine $(24 \mu \mathrm{Ci} / \mathrm{ml})$ were added to cells 10 minutes before harvesting, whereas $\left[{ }^{3} \mathrm{H}\right]$ thymidine $(48 \mu \mathrm{Ci} / \mathrm{ml})$ was added to cells 20 minutes before harvesting. For protein labeling, $\left[{ }^{35} \mathrm{~S}\right]$ methionine was added in methionine-free medium supplemented with $10 \%$ dialyzed FCS. For $\left[{ }^{3} \mathrm{H}\right]$ uridine and $\left[{ }^{3} \mathrm{H}\right]$ thymidine labeling, the isotopes were added in DMEM supplemented with $10 \%$ dialyzed FCS. Cells where then collected and lysed in RIPA buffer $(50 \mathrm{mM}$ Tris-HCl, $\mathrm{pH} 7.5,150 \mathrm{mM} \mathrm{NaCl}, 1.0 \% \mathrm{NP}-40,0.5 \%$ sodium deoxycholate, $0.1 \% \mathrm{SDS}$ ). Radiolabeled proteins were isolated by TCA precipitation on Whatman $3 \mathrm{MM}$ paper. Radiolabeled nucleic acids were isolated by filtration through Whatman GF/C glass fiber filters. The amount of radioactivity was determined by scintillation counting, and the counts were normalized to protein concentration, which had been determined using a modified Lowry assay (DC Protein Assay; Bio-Rad).

Ribosome binding and chemical cross-linking. Ribosome binding assays were performed by incubating [ $\left.{ }^{32} \mathrm{P}\right]$-labeled CAT $\mathrm{mRNA}$ in rabbit reticulocyte lysate in the presence of $600 \mu \mathrm{M}$ cycloheximide (CHX), vehicle $(\mathrm{MeOH})$, or $100 \mu \mathrm{M} \mathrm{FA}$ at $30^{\circ} \mathrm{C}$ for 10 minutes (23). Following centrifugation through $10 \%-30 \%$ glycerol gradients (SW40; $187,000 \mathrm{~g} / 3.5$ hours), fractions from each gradient were collected using a Brandel Tube Piercer connected to an ISCO fraction collector. Fractions of $500 \mu \mathrm{l}$ were collected, and radioactivity was determined by scintillation counting.

Chemical cross-linking of initiation factor preparations to [ $\left.{ }^{32} \mathrm{P}\right]$-caplabeled oxidized CAT mRNA was performed under standard reaction conditions (30) containing $0.9 \mathrm{mM}$ ATP. For chemical cross-linking with individual factors, $1 \mu \mathrm{g}$ of recombinant eIF4AI $\mathrm{f}_{\mathrm{f}}, 1 \mu \mathrm{g}$ Ded1, or $0.7 \mu \mathrm{g}$ eIF4F was used. After cross-linking, samples were treated with RNase A and separated on $10 \%-15 \%$ SDS-PAGE gradient gels (for ribosomal salt wash preparations) or $10 \%$ SDS-PAGE gels (for eIF4A $\mathrm{A}_{\mathrm{f}}$ or eIF4F). The gels were dried and exposed to X-Omat (Kodak) film at $-70^{\circ} \mathrm{C}$ with an intensifying screen.

Polysome profiling and Western blotting. Polysome profiles were generated as previously described (42). Briefly, $2 \times 10^{7} \mathrm{Jurkat}$ cells were incubated with vehicle $(\mathrm{MeOH})$ or $0.2 \mu \mathrm{M}$ silvestrol for 1 hour. For polysome profiling performed with the $P t_{e n}^{+/-E} \mu-M y c$ tumors, lymphomas were extracted from the animals following a 4-hour treatment with vehicle $(\mathrm{MeOH})$ or $1.0 \mathrm{mg} / \mathrm{kg}$ silvestrol. In both cases, cells were then harvested and lysed in buffer A $(5 \mathrm{mM}$ Tris, pH 7.5, $2.5 \mathrm{mM} \mathrm{MgCl}_{2}, 1.5 \mathrm{mM} \mathrm{KCl}, 2$ mM DTT, 1\% Triton X-100, 0.5\% sodium deoxycholate) in the presence of $100 \mu \mathrm{g} / \mathrm{ml}$ cycloheximide. Where indicated, the supernatants were treated with micrococcal nuclease by incubation at room temperature with $1 \mathrm{mM} \mathrm{CaCl}_{2}$ and $100 \mathrm{U} / \mathrm{ml}$ of micrococcal nuclease for 20 minutes, followed by termination of the reaction by addition of 2 mM EGTA. The lysates were loaded onto $10 \%-50 \%$ sucrose gradients and centrifuged in an SW40 rotor at 150,000 $\mathrm{g}$ for 2 hours. Fractions were collected, and absorbance was monitored during the process. The fractions were then resolved on $10 \%$ SDS-PAGE gels and proteins visualized by Western blotting using anti-eIF4A(5D3) (64), anti-eIF4E (BD Biosciences Inc.), and anti-eIF4G1 (Bethyl Laboratories Inc.) antibodies.

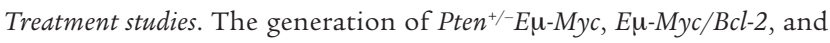
EM-Myc/eIF4E lymphomas has been described elsewhere $(9,10)$. A total of $2 \times 10^{6}$ secondary lymphoma cells was injected into the tail vein of 6- to 8-week-old female C57BL/6 mice. Upon development of well-palpable tumors (auxiliary and inguinal lymph nodes), mice were injected intraperitoneally with doxorubicin (once at $10 \mathrm{mg} / \mathrm{kg}$ ), rapamycin $(4 \mathrm{mg} / \mathrm{kg}$ daily for 5 days), silvestrol ( $0.2 \mathrm{mg} / \mathrm{kg}$ daily for 5 days). Rapamycin, doxorubicin, and silvestrol were diluted in 5.2\% PEG400/5.2\% Tween-80 immediately prior to intraperitoneal injection. In combination studies, silvestrol or rapamycin were administered once daily for 5 consecutive days, while doxorubicin was administered on day 2 . Tumor-free survival is defined as the time between disappearance and reappearance of a palpable lymphoma following treatment. All animal studies were approved by the McGill University Faculty of Medicine Animal Care Committee.

Statistics. The data were analyzed in the Kaplan-Meier format using the log-rank (Mantel-Cox) test for statistical significance (SigmaStat software). $P$ values of less than 0.001 were considered significant.

\section{Acknowledgments}

We thank John Mills for critical reading of the manuscript. We are grateful to Murray Tait (Cerylid Biosciences Ltd. Australia) for the generous supply of silvestrol. M-E. Bordeleau was supported by a Canadian Institutes of Health Research (CIHR) Cancer Consortium Training Grant Award and a Fonds de la recherche en santé du Québec studentship award. B. Gerard was supported by a grant from the NIH. L. Lindqvist was supported by a CIHR Chemical Biology Fellowship and a Maysie MacSporran studentship. This work was supported by grants from the National Cancer Institute of Canada (no. 017099) and the CIHR (MOP-79385) to J. Pelletier; an NIH R01 grant (GM073855) to J.A. Porco Jr.; and National Cancer Institute grant CA87497 to S.W. Lowe.

Received for publication December 13, 2007, and accepted in revised form May 7, 2008.

Address correspondence to: Jerry Pelletier, McIntyre Medical Sciences Building, Room 810, 3655 Promenade Sir William Osler, McGill University, Montreal, Quebec H3G 1Y6, Canada. Phone: (514) 3982323; Fax: (514) 398-7384; E-mail: jerry.pelletier@mcgill.ca.

Marie-Eve Bordeleau and Francis Robert contributed equally to this work.
1. Raught, B., Gingras, A.-C., and Sonenberg, N. 2000. Regulation of ribosome recruitment in eukaryotes. Cold Spring Harbor Laboratory Press. Cold Spring Harbor, New York, USA. 245-293

2. Pestova, T.V., et al. 2001. Molecular mechanisms of translation initiation in eukaryotes. Proc. Natl. Acad. Sci. U. S. A. 98:7029-7036.

3. Dorrello, N.V., et al. 2006. S6K1- and betaTRCPmediated degradation of PDCD4 promotes protein translation and cell growth. Science. 314:467-471.

4. Yang, H.S., et al. 2003. The transformation suppressor Pdcd4 is a novel eukaryotic translation initiation factor $4 \mathrm{~A}$ binding protein that inhibits translation. Mol. Cell. Biol. 23:26-37.

5. Avdulov, S., et al. 2004. Activation of translation complex eIF4F is essential for the genesis and maintenance of the malignant phenotype in human mammary epithelial cells. Cancer Cell. 5:553-563.

6. Lazaris-Karatzas, A., Montine, K.S., and Sonenberg, N. 1990. Malignant transformation by a eukaryotic initiation factor subunit that binds to mRNA 5 cap. Nature. 345:544-547.

7. Fukuchi-Shimogori, T., et al. 1997. Malignant transformation by overproduction of translation initiation factor eIF4G. Cancer Res. 57:5041-5044.

8. Zhang, L., Pan, X., and Hershey, J.W. 2007. Individual overexpression of five subunits of human translation initiation factor eIF3 promotes malignant transformation of immortal fibroblast cells. J. Biol. Chem. 282:5790-5800.

9. Wendel, H.-G., et al. 2004. Survival signalling by Akt and eIF4E in oncogenesis and cancer therapy. Nature. 428:332-337.

10. Wendel, H.G., et al. 2006. Determinants of sensitiv- ity and resistance to rapamycin-chemotherapy drug combinations in vivo. Cancer Res 66:7639-7646.

11. Ruggero, D., et al. 2004. The translation factor eIF-4E promotes tumor formation and cooperates with c-Myc in lymphomagenesis. Nat. Med. 10:484-486.

12. Polunovsky, V.A., et al. 1996. Translational control of programmed cell death: eukaryotic translation initiation factor 4E blocks apoptosis in growthfactor-restricted fibroblasts with physiologically expressed or deregulated Myc. Mol. Cell. Biol. 16:6573-6581.

13. Tan, A., Bitterman, P., Sonenberg, N., Peterson, M., and Polunovsky, V. 2000. Inhibition of Mycdependent apoptosis by eukaryotic translation initiation factor $4 \mathrm{E}$ requires cyclin D1. Oncogene. 19:1437-1447.

14. Li, S., et al. 2003. Translation factor eIF4E rescues 
cells from Myc-dependent apoptosis by inhibiting cytochrome c release. J. Biol. Chem. 278:3015-3022.

15. Grolleau, A., et al. 2002. Global and specific translational control by rapamycin in $\mathrm{T}$ cells uncovered by microarrays and proteomics. J. Biol. Chem. 277:22175-22184

16. Rajasekhar, V.K., et al. 2003. Oncogenic Ras and Akt signaling contribute to glioblastoma formation by differential recruitment of existing mRNAs to polysomes. Mol. Cell. 12:889-901.

17. Mamane, Y., et al. 2007. Epigenetic activation of a subset of mRNAs by eIF4E explains its effects on cell proliferation. PLoS ONE. 2:e242.

18. Rousseau, D., Gingras, A.C., Pause, A., and Sonenberg, N. 1996. The eIF4E-binding proteins 1 and 2 are negative regulators of cell growth. Oncogene. 13:2415-2420.

19. De Benedetti, A., Joshi-Barve, S., Rinker-Schaeffer, C., and Rhoads, R.E. 1991. Expression of antisense RNA against initiation factor eIF-4E mRNA in $\mathrm{HeLa}$ cells results in lengthened cell division times, diminished translation rates, and reduced levels of both eIF-4E and the p220 component of eIF-4F. Mol. Cell. Biol. 11:5435-5445.

20. Graff, J.R., et al. 2007. Therapeutic suppression of translation initiation factor eIF4E expression reduces tumor growth without toxicity. J. Clin. Invest. 117:2638-2648.

21. Jansen, A.P., Camalier, C.E., and Colburn, N.H. 2005. Epidermal expression of the translation inhibitor programmed cell death 4 suppresses tumorigenesis. Cancer Res. 65:6034-6041.

22. Hwang, B.Y., et al. 2004. Silvestrol and episilvestrol, potential anticancer rocaglate derivatives from Aglaia silvestris. J. Org. Chem. 69:3350-3358.

23. Novac, O., Guenier, A.S., and Pelletier, J. 2004. Inhibitors of protein synthesis identified by a high throughput multiplexed translation screen. Nucleic Acids Res. 32:902-915.

24. Hausott, B., Greger, H., and Marian, B. 2004. Flavaglines: a group of efficient growth inhibitors block cell cycle progression and induce apoptosis in colorectal cancer cells. Int. J. Cancer. 109:933-940.

25. Lee, S.K., Cui, B., Mehta, R.R., Kinghorn, A.D., and Pezzuto, J.M. 1998. Cytostatic mechanism and antitumor potential of novel $1 \mathrm{H}$-cyclopenta[b]benzofuran lignans isolated from Aglaia elliptica. Chem. Biol. Interact. 115:215-228.

26. Kim, S., et al. 2006. Cytotoxic flavaglines and bisamides from Aglaia edulis. J. Nat. Prod. 69:1769-1775

27. Mi, Q., et al. 2006. Rocaglaol induces apoptosis and cell cycle arrest in LNCaP cells. Anticancer Res. 26:947-952.

28. Kim, S., Salim, A.A., Swanson, S.M., and Kinghorn, A.D. 2006. Potential of cyclopenta[b]benzofurans from Aglaia species in cancer chemotherapy. Anticancer Agents Med. Chem. 6:319-345.

29. Ohse, T., Ohba, S., Yamamoto, T., Koyano, T., and Umezawa, K. 1996. Cyclopentabenzofuran lignan protein synthesis inhibitors from Aglaia odorata. J. Nat. Prod. 59:650-652

30. Sonenberg, N. 1981. ATP/Mg++-dependent crosslinking of cap binding proteins to the $5^{\prime}$ end of eukaryotic mRNA. Nucleic Acids Res. 9:1643-1656.

31. Pause, A., Methot, N., Svitkin, Y., Merrick, W.C., and Sonenberg, N. 1994. Dominant negative mutants of mammalian translation initiation factor eIF-4A define a critical role for eIF-4F in cap-dependent and cap-independent initiation of translation. EMBO J. 13:1205-1215.

32. Yoder-Hill, J., Pause, A., Sonenberg, N., and Merrick, W.C. 1993. The p46 subunit of eukaryotic initiation factor (eIF)-4F exchanges with eIF-4A. J. Biol. Chem. 268:5566-5573.

33. Rocak, S., and Linder, P. 2004. DEAD-box proteins: the driving forces behind RNA metabolism. Nat. Rev. Mol. Cell Biol. 5:232-241.

34. Jurica, M.S., and Moore, M.J. 2003. Pre-mRNA splicing: awash in a sea of proteins. Mol. Cell. 12:5-14.

35. Holcik, M., Gibson, H., and Korneluk, R.G. 2001. XIAP: apoptotic brake and promising therapeutic target. Apoptosis. 6:253-261.

36. Polunovsky, V.A., et al. 2000. Translational control of the antiapoptotic function of Ras. J. Biol. Chem. 275:24776-24780.

37. Li, S., et al. 2002. Translational control of cell fate: availability of phosphorylation sites on translational repressor 4E-BP1 governs its proapoptotic potency. Mol. Cell. Biol. 22:2853-2861.

38. Schneider, R.J., and Sonenberg, N. 2007. Translational control in cancer development and progression. In Translational control in biology and medicine. M.B. Mathews, N. Sonenberg, and J.W.B. Hershey, editors. Cold Spring Harbor Laboratory Press. Cold Spring Harbor, New York, USA. 934 pp.

39. Svitkin, Y.V., et al. 2001. The requirement for eukaryotic initiation factor $4 \mathrm{~A}$ (elF4A) in translation is in direct proportion to the degree of mRNA 5 ' secondary structure. RNA. 7:382-394.

40. Larsson, O., et al. 2006. Apoptosis resistance downstream of eIF4E: posttranscriptional activation of an anti-apoptotic transcript carrying a consensus hairpin structure. Nucleic Acids Res. 34:4375-4386.

41. Bordeleau, M.E., et al. 2005. Stimulation of mammalian translation initiation factor eIF4A activity by a small molecule inhibitor of eukaryotic translation. Proc. Natl. Acad Sci. U. S. A. 102:10460-10465.

42. Bordeleau, M.E., et al. 2006. RNA-mediated sequestration of the RNA helicase eIF4A by Pateamine A inhibits translation initiation. Chem. Biol. 13:1287-1295.

43. Mi, Q., et al. 2006. Silvestrol regulates G2/M checkpoint genes independent of p53 activity. Anticancer Res. 26:3349-3356.

44. Proksch, P., et al. 2005. Rocaglamide derivatives are immunosuppressive phytochemicals that target NF-AT activity in T cells. J. Immunol. 174:7075-7084.

45. Baumann, B., et al. 2002. Rocaglamide derivatives are potent inhibitors of NF- $\mathrm{\kappa B}$ activation in T-cells. J. Biol. Chem. 277:44791-44800.

46. Bordeleau, M.-E., et al. 2006. Functional characterization of IRESes by an inhibitor of the RNA helicase eIF4A. Nat. Chem. Biol. 2:213-220.

47. Wang, H., et al. 2002. Dendritic BC1 RNA: functional role in regulation of translation initiation. J. Neurosci. 22:10232-10241.

48. Wang, H., et al. 2005. Dendritic BC1 RNA in translational control mechanisms. J. Cell Biol. 171:811-821.

49. Eberle, J., Krasagakis, K., and Orfanos, C.E. 1997. Translation initiation factor eIF-4A 1 mRNA is consistently overexpressed in human melanoma cells in vitro. Int. J. Cancer. 71:396-401.

50. Shuda, M., et al. 2000. Enhanced expression of translation factor mRNAs in hepatocellular carcinoma. Anticancer Res. 20:2489-2494.

51. Jansen, A.P., Camalier, C.E., Stark, C., and Colburn, N.H. 2004. Characterization of programmed cell death 4 in multiple human cancers reveals a novel enhancer of drug sensitivity. Mol. Cancer Ther. 3:103-110.

52. Li, B.D., Liu, L., Dawson, M., and De Benedetti, A. 1997. Overexpression of eukaryotic initiation factor 4E (eIF4E) in breast carcinoma. Cancer. 79:2385-2390.

53. Rosenwald, I.B. 2004. The role of translation in neoplastic transformation from a pathologist's point of view. Oncogene. 23:3230-3247.

54. Martin, M.E., et al. 2000. 4E binding protein 1 expression is inversely correlated to the progression of gastrointestinal cancers. Int. J. Biochem. Cell Biol. 32:633-642.

55. Faivre, S., Kroemer, G., and Raymond, E. 2006. Current development of mTOR inhibitors as anticancer agents. Nat. Rev. Drug Discov. 5:671-688.

56. O'Reilly, K.E., et al. 2006. mTOR inhibition induces upstream receptor tyrosine kinase signaling and activates Akt. Cancer Res. 66:1500-1508.

57. Zeng, Z., et al. 2007. Rapamycin derivatives reduce mTORC2 signaling and inhibit AKT activation in AML. Blood. 109:3509-3512.

58. Sarbassov, D.D., et al. 2006. Prolonged rapamycin treatment inhibits mTORC2 assembly and Akt/ PKB. Mol. Cell. 22:159-168.

59. Guertin, D.A., and Sabatini, D.M. 2007. Defining the role of mTOR in cancer. Cancer Cell. 12:9-22.

60. Kim, S., et al. 2007. Silvestrol, a potential anticancer rocaglate derivative from Aglaia foveolata, induces apoptosis in LNCaP cells through the mitochondrial/apoptosome pathway without activation of executioner caspase- 3 or -7 . Anticancer Res. 27:2175-2183.

61. Greger, H., Pacher, T., Brem, B., Bacher, M., and Hofer, O. 2001. Insecticidal flavaglines and other compounds from Fijian Aglaia species. Phytochemistry. 57:57-64.

62. Gerard, B., Sangji, S., O'Leary, D.J., and Porco, J.A., Jr. 2006. Enantioselective photocycloaddition mediated by chiral Bronsted acids: asymmetric synthesis of the rocaglamides. J. Am. Chem. Soc. 128:7754-7755.

63. Meurer-Grimes, B.M., Yu, J, and Vairo, G.L. 2004 Therapeutic compounds and methods. US Patent 6710075,28 , filed Nov. 8, 2002, and issued Mar. 23, 2004.

64. Edery, I., et al. 1983. Involvement of eukaryotic initiation factor $4 \mathrm{~A}$ in the cap recognition process. J. Biol. Chem. 258:11398-11403.

65. Grollman, A.P. 1967. Inhibitors of protein biosynthesis. II. Mode of action of anisomycin. J. Biol. Chem. 242:3226-3233. 